OPEN ACCESS

Edited by:

Allison E. Ray,

Idaho National Laboratory,

United States

Reviewed by:

Muhammad Aziz,

Tokyo Institute of Technology, Japan

Wenjian Guan,

Harvard University, United States

${ }^{*}$ Correspondence:

Xiaowen Chen

xiaowen.chen@nrel.gov

Specialty section: This article was submitted to Bioenergy and Biofuels, a section of the journal

Frontiers in Energy Research

Received: 09 April 2018 Accepted: 30 May 2018

Published: 19 June 2018

Citation:

Chen X, Kuhn E, Nagle N, Nelson $R$,

Tao L, Crawford $N$ and Tucker $M$

(2018) Recycling of Dilute

Deacetylation Black Liquor to Enable Efficient Recovery and Reuse of Spent Chemicals and Biomass Pretreatment Waste. Front. Energy Res. 6:51. doi: 10.3389/fenrg.2018.00051

\section{Recycling of Dilute Deacetylation Black Liquor to Enable Efficient Recovery and Reuse of Spent Chemicals and Biomass Pretreatment Waste}

\author{
Xiaowen Chen ${ }^{1 *}$, Erik Kuhn ${ }^{1}$, Nick Nagle ${ }^{1}$, Robert Nelson ${ }^{1}$, Ling Tao ${ }^{1}$, Nathan Crawford ${ }^{2}$ \\ and Melvin Tucker ${ }^{1}$
}

${ }^{1}$ National Renewable Energy Laboratory, National Bioenergy Center, Golden, CO, United States, ${ }^{2}$ Thermo Fisher Scientific, Lafayette, CO, United States

Deacetylation/dilute alkaline pretreatment followed by mechanical refining (DMR) has been proven as an effective process for biomass sugar liberation without severe chemical modification to lignin. Previous research has been focused on optimizing deacetylation conditions, reducing energy consumptions in mechanical refining, and improving sugar yields and titers in enzymatic hydrolysis. To successfully commercialize this process, another critical challenge is to develop a robust process to balance water usage, recover spent chemicals, and utilize waste carbons from the dilute deacetylation waste liquor. In this work, a new process modification and strategy is pioneered to recycle and reuse the weak black liquor (WBL) in order to reduce water, chemical, and energy usage while increasing both inorganic and organic contents in the WBLto facilitate downstream processing. Results suggest that the accumulation did not lower acetyl and lignin removal in alkaline pretreatment, resulting in comparable sugar yields in enzymatic hydrolysis. Sodium and potassium were found to be the two most important inorganic compounds in the recycled WBL. Moreover, the accumulated sodium and phenolic compounds did not inhibit the downstream ethanol fermentation processes. Finally, techno-economic analysis (TEA) showed a decrease in the minimum ethanol selling price (MESP) by $\sim 5$ to 15 cents per gallon of ethanol resulting from the inclusion of the recycling of weak black liquor when compared to a conventional non-recycling process.

Keywords: deacetylation and mechanical refining, DMR, black liquor recycling, bioethanol production, minimum ethanol selling price

\section{INTRODUCTION}

The Deacetylation and Mechanical Refining (DMR) process deconstructs and fractionates biomass into low toxicity, high concentration sugar syrups that have been demonstrated to be highly fermentable to ethanol with high ethanol yields, titers, and productivities (Chen et al., 2016), as well as highly reactive, tractable lignin streams that have been demonstrated to be upgradable to biojet fuel blendstocks and other bioproducts (Laskar et al., 2014; Jeon et al., 2015; Wang et al., 2015, 2017). However, to successfully commercialize alkaline-based pretreatments, including dilute 
alkali deacetylation, alkali recovery, and recycling are equally critical as the sugar yields in terms of economic feasibility and environmental impacts.

The major role of alkali, primarily sodium hydroxide $(\mathrm{NaOH})$, in deacetylation/dilute alkaline pretreatments is to catalyze the saponification of acetyl groups from hemicellulose and partially delignify the biomass (Chen et al., 2012). The liberated acetic acid will then be neutralized by sodium hydroxide to form sodium acetate, lowering the $\mathrm{pH}$ of the deacetylation liquor. In the deacetylation of corn stover feedstocks, $\sim 10-30 \%$ of the solids in the biomass were found solubilized, including $70-80 \%$ of the acetate, $2-10 \%$ of the xylan, $1 \%$ of the glucan, and $20-40 \%$ of the lignin, which forms a weak black liquor (WBL) along with spent chemicals (Chen et al., 2012). The WBL is then separated from the biomass by draining and washing potentially recovering the spent chemicals, especially the sodium, to reduce environmental impacts, capitial, operational, and disposal costs.

The recovery of sodium hydroxide from the deacetylation/dilute alkaline pretreatment step can potentially utilize similar equipment and causticizing processes as used in the Kraft pulping industry. Figure 1 shows the typical Kraft sodium hydroxide recovery process (Tran and Vakkilainnen, 2008). After Kraft pulping, a stream of WBL containing 15\% total solids including spent chemicals and solubilized biomass is produced as a waste liquor stream from the digester. Then the weak black liquor is concentrated in multi-effect evaporators to more than $65-80 \%$ total solids to allow effective burning in a recovery boiler. The heavy black liquor is then sprayed and burned in the lower part of the recovery boiler where sodium salts are formed under an oxygen deficient environment. The formed sodium salt smelt, mainly containing sodium carbonate $\left(\mathrm{Na}_{2} \mathrm{CO}_{3}\right)$ and sodium sulfide $\left(\mathrm{Na}_{2} \mathrm{~S}\right)$, are leached in water forming the so-called green liquor, which later reacts with lime (calcium hydroxide) to regenerate sodium hydroxide in the causticizing process. The precipitated byproduct of calcium carbonate is then regenerated back to quicklime $(\mathrm{CaO})$ in the lime kiln and slaked with water to form lime for recycle. The recovery efficiencies for sodium have been reported as high as 97\% in the Kraft process (Tran and Vakkilainnen, 2008).

Although the Kraft sodium recovery process is a mature and commercially available process, the direct application of this technology to WBL from the deacetylation/dilute alkaline pretreatment step in a biorefinery industry remains challenging. DMR requires a much lower sodium hydroxide loading compared to the Kraft pulping process (0.4-2 wt\% compared to 15-18 wt\%) designed to remove most of the lignin and hemicellulose to make white paper. Recent research conducted at the National Renewable Energy Laboratory (NREL) demonstrated that deacetylation of corn stover with $0.5 \mathrm{wt} \%$ $\mathrm{NaOH}$ ( $50 \mathrm{~kg} /$ ton of biomass) followed by mechanical refining, resulted in a residual solids containing $10 \%$ lignin $(1 / 2-2 / 3$ of original lignin content of the biomass) and $30 \%$ xylan (90\% of original xylan content), and can reach $>80 \%$ glucose yields in enzymatic hydrolysis with an enzyme loading of $10 \mathrm{mg}$ protein/g of cellulose (Chen et al., 2016). The lower sodium hydroxide loading due to the lower requirements of biomass delignification for deacetylation/dilute alkali pretreatments significantly reduces the energy demand and capacity required for the recovery boiler and energy demand required in the lime kiln. In addition, lower sodium hydroxide loading reduces the hemicellulose degradation due to peeling reaction and thus improve overall sugar yields. The lower loading of sodium hydroxide, lower temperatures used in the DMR process as compared to the Kraft process, results in less organic substances are extracted and/or hydrolyzed in the deacetylation step, leading to more dilute WBLs. In addition, previous reported deacetylation/dilute alkaline pretreatment used a solid-to-liquid ratio of 1:10 followed by an extensive washing step using the same solids-to-water ratio. The large quantity of water usage not only increases the operational costs due to evaporation energy required for recovery and significantly increases the capital and operational expenditures required of wastewater treatment. The dilute WBL from DMR process cannot be direcly combusted in recovery boiler due to the low organic contents/heating value present. Even with recent improvments for an advanced Kraft process, to include gasification of the black liquor and the co-prodution electricity (Naqvi et al., 2012; Darmawan et al., 2018), direct gasification of WBL could be problematic due to the presence of large amount of water. Similar reasons also make direct evaporation of WBL to the solids level suitable for combustion or gasification ( $\geq 65 \%$ ) not economical nor energy efficient.

To provide a solution to address these issues, we pioneered a new process modification and strategy to recycle and reuse the WBL to reduce water, chemical, and energy usage while increasing the solids, sodium, acetate, sugars, and lignin contents in the WBL. Figure 2 shows a schematic diagram of the black liquor recycling scheme. WBL from the first batch of deacetylation is separated from the biomass and additional water and sodium hydroxide are added for that required for deacetylation of the second batch of fresh corn stover biomass at the 1:10 solids-to-liquid ratio. The same procedure is repeated for the $n$th time (here in this stud biomassy $n=6$ ) until the thickened black liquor (TBL) is purged. Meanwhile, a clean water stream is used to wash the deacetylated biomass in a counter-current

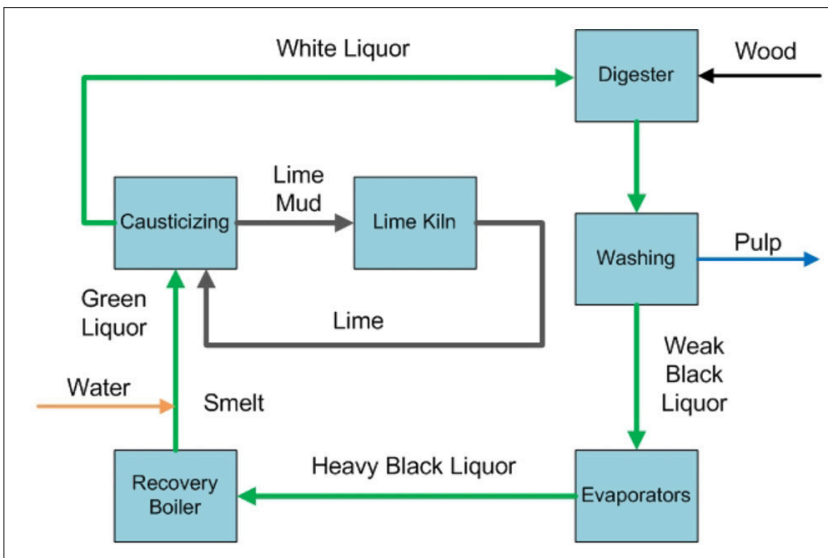

FIGURE 1 | Typical chemical (sodium and lye/lime) recovery process in the Kraft pulping industry. 


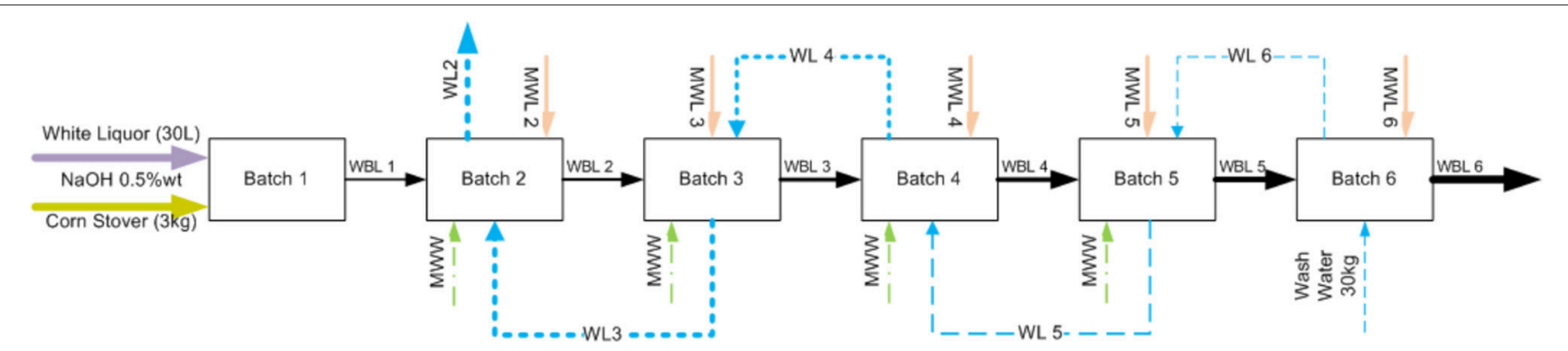

FIGURE 2 | Schematic diagram of proposed weak black liquor recycling. WBL, weak black liquor; MWW, makeup wash water; MWL, makeup white liquor; WL, wash liquor.

reverse batch-wise sequence. The washing is not performed once the soluble solids in the wash liquor is equivalent to the total solids of the deacetylation liquor at the $i$ th stage (here $i=1$ ), at which point the water was recycled five times until the final total soluble solids concentration reached $\sim 9 \mathrm{wt} \%$.

As shown in Figure 2, WBL from the upstream deacetylation step is used as a base liquor to extract a new batch of biomass so that the extracted organic substances and spent sodium will accumulate. The accumulation of both chemicals and organic matter enables efficient chemical recovery, but could potentially reduce the acetyl and lignin removal, leading to significantly lower enzymatic digestibility of the extracted biomass. Our results suggest otherwise. The accumulated sodium and phenolic compounds could also inhibit the downstream fermentation and catalytic upgrading processes. Again, our results suggest otherwise. Therefore, in this study, we investigated the effects of recycling of the weak black liquor from each batch stage on acetyl and lignin removal, biomass digestibility, enzymatic hydrolysis yield, and hydrolyzate fermentability. The hydrolyzate fermentability was investigated using ethanologen (recombinant Zymomonas13-H-9-2). Finally, the process and economic benefits of recycling weak black liquor were simulated using Aspen plus and economic models.

\section{METHODS}

\section{Feedstock}

Corn stover harvested in 2009 in Hurley, South Dakota, and transported to Idaho National Laboratory (INL) was hammer milled and stored indoors. Upon receipt at NREL in 2013, the corn stover was further knife milled (Jordan Reduction Solutions, model $14 \times 20$, Birmingham, Alabama) to allow passing through a rejection screen with $19 \mathrm{~mm}$ (3/4-inch) round holes and stored indoors in $200 \mathrm{~kg}$ lots in super sacks at room temperature.

\section{Bench-Scale Deacetylation and Black Liquor Recycling}

Corn stover deacetylation was performed in a 90-L paddle reactor following the sequence described in Figure 1. The individual operation as described earlier (Chen et al., 2012). Dry corn stover $(3.0$ dry $\mathrm{kg}$ ) was added to the reactor along with $30 \mathrm{~kg}$ of white liquor or $30 \mathrm{~kg}$ of recycled black liquor with makeup water and sodium hydroxide. The white liquor was made by mixing $0.165 \mathrm{~kg}$ sodium hydroxide pellets with $29.6 \mathrm{~kg}$ of tap water $(0.3 \mathrm{~kg}$ of additional water came in with the biomass). The $30 \mathrm{~kg}$ of black liquor in the WBL from a previous deacetylation batch run was mixed with makeup water and $0.165 \mathrm{~kg}$ of sodium hydroxide. Because the $\mathrm{pH}$ of the spent deacetylation weak black liquor was near neutral, indicating the $\mathrm{NaOH}$ was titrated by the acetic acid released, the same quantity of sodium hydroxide was required to be added in the makeup white liquor. The WBL was drained through an 8 -inch screen ( $\sim 2 \mathrm{~mm}$ wire spacing) followed by pressing using a Vincent screw press (Vincent Corporation, model CP-4, Tampa, Florida). The makeup water was calculated based on the amount of WBL obtained, which is further discussed in the Results and Discussion section. The slurry for the next $i$ th batch deacetylation step was heated to $80^{\circ} \mathrm{C}$ and held for $2 \mathrm{~h}$, and then the weak black liquor was allowed to drain overnight through an 8-inch screen located in the bottom port of the paddle mixer.

The screw-pressed deacetylated corn stover was washed following the sequence described in Figure 2. Batch 6 deacetylated corn stover solids were washed with $30 \mathrm{~kg}$ of fresh water in the paddle reactor for $30 \mathrm{~min}$. The wash water was drained through the 8-inch screen and the slurry is further dewatered again through the Vincent screw press. The wash water was collected and weighed. Approximately $7 \mathrm{~kg}$ of fresh makeup water for each batch washing step was used to achieve a total of $30 \mathrm{~kg}$ of washing liquor for each batch of deacetylated biomass, keeping the solids-to-liquid ratio of 1:10. The washing was not performed on batch 1 since the solids of the recycled washing liquor was equivalent to the solids in the black liquor exiting from batch 1 , and no further washing is expected to take place.

\section{Szego Milling}

The refining with the Szego mill was, previously described (Chen et al., 2014), performed at a measured rotational speed of $1,160 \mathrm{rpm}$. The biomass was fed at a rate of $\sim 100 \mathrm{~kg} / \mathrm{h}$ with approximate solids of $10 \%$. The refining energy required for the first pass through the Szego mill was measured at $\sim 70$ $\mathrm{kWh} /$ oven dried metric ton (ODMT) using a Fluke model 1,735 Power Logger (Fluke Corporation, Everett, Washington), while the second pass through the Szego mill was measured 
at $\sim 30 \mathrm{kWh} / \mathrm{ODMT}$. Therefore, a total energy input of $\sim 100$ $\mathrm{kWh} / \mathrm{ODMT}$ was used in the two-stage refining step. The twostage refined solids were loaded into close-mesh laundry bags and dewatered using a GE washing machine on the spin cycle prior to enzymatic hydrolysis.

\section{Enzymatic Hydrolysis}

Prior to enzyme hydrolysis, the deacetylated and mechanically refined corn stover substrates were slowly and carefully titrated with ammonium hydroxide to a $\mathrm{pH}$ of 5.3 in a 30 -liter industrial dough mixer. Then $4 \mathrm{~kg}$ of the $\mathrm{pH}$ adjusted substrate was autoclaved at $121^{\circ} \mathrm{C}$ for $30 \mathrm{~min}$. The cellulase/hemicellulase enzyme cocktails and additional water were added to the final required total solids concentrations at $20 \mathrm{wt} \%$ solids. The hydrolysis were carried out in 9-liter stainless steel roller bottle vessels with a mixing speed at $19 \mathrm{rpm}$. About $1,000 \mathrm{~g}$ of biomass substrate at the required solids loadings were.enzymatically saccharified using Novozymes Cellic CTec3 at a loading of 16 $\mathrm{mg} / \mathrm{g}$ of cellulose along with Cellic HTec 3 at $4 \mathrm{mg} / \mathrm{g}$ of cellulose at $50^{\circ} \mathrm{C}$ for $120 \mathrm{~h}$.

\section{Ethanol Fermentation}

To test the toxicity of the effect of residue salts in biomass on subsequent ethanol fermentation, the NREL engineered strain, Zymomonas mobilis 13-H-9-2 (Chen et al., 2016), was selected for this work. All fermentations were carried out at $300 \mathrm{ml}$ working volumes in BioStat-Q Plus fermenters using enzymatic hydrolyzed DMR substrates. No extra washing of the substrates was performed. The fermentation conditions were as follows: temperature at $33^{\circ} \mathrm{C}, \mathrm{pH}$ at 5.8 (controlled with $4 \mathrm{~N}$ potassium hydroxide $[\mathrm{KOH}]$ ), and agitation speed at $300 \mathrm{rpm}$. Ethanol yields were calculated using the methods mentioned elsewhere(Mohagheghi et al., 2004).

\section{Analytical Methods}

All analytic methods used in this work were following the NREL standard Laboratory Analysis Procedure (LAP) including solids compositional analysis by LAP No. NREL/TP-510-42627 (Sluiter et al., 2008a,b), and soluble sugars, acetic acid, and degradation product determined by LAP No. NREL/TP-510-42623 (Sluiter et al., 2008a). Pretreated biomass insoluble solid concentrations were determined by a six-step washing and centrifugation procedure (Schell et al., 2003).

\section{Viscosity Measurement}

Rheological experiments were conducted using a Bohlin Gemini HR nano stress-controlled rheometer (Malvern Instruments, Westborough, Massachusetts) equipped with a $40 \mathrm{~mm}, 4^{\circ}$ stainless steel cone-and-plate geometry. Temperature control of $\pm 0.1^{\circ} \mathrm{C}$ was provided by the bottom, Peltier effect plate. The truncation gap height of the cone was specified at $150 \mu \mathrm{m}$.

The viscosity of the black liquors was investigated as a function of temperature at $25,50,75,90$, and $100^{\circ} \mathrm{C}$ (temperatures above $100^{\circ} \mathrm{C}$ were explored, but the liquors began to boil and the resulting viscosity measurements were erroneous). Initially, liquor (sample volume of $\sim 1.5 \mathrm{~mL}$ ) was loaded onto the rheometer at $25^{\circ} \mathrm{C}$ and allowed to equilibrate for $2 \mathrm{~min}$ before commencing rheological measurements. After equilibration, the sample was preheated at $100 \mathrm{~s}^{-1}$ for $1 \mathrm{~min}$. Then data was collected every $10 \mathrm{~s}$ at a constant shear rate of $100 \mathrm{~s}^{-1}$ for a total of $2 \mathrm{~min}$. After shearing at $25^{\circ} \mathrm{C}$, the temperature was increased to $50^{\circ} \mathrm{C}$ and again allowed to equilibrate for $2 \mathrm{~min}$. The sample was then presheared and sheared at $100 \mathrm{~s}^{-1}$, collecting data every $10 \mathrm{~s}$ over a 2 min duration. At every new temperature, the sample was equilibrated for $2 \mathrm{~min}$ and the same preshear and shear procedure described above was followed. Experiments were repeated in duplicate to verify reproducibility.

\section{RESULTS AND DISCUSSION \\ Effect of Recycling Black Liquor on Water Consumption}

Table 1 shows the water consumption in this black liquor recycling study. For batch 1, the deacetylation white liquor was made by adding $0.165 \mathrm{~kg}$ of sodium hydroxide to $29.6 \mathrm{~kg}$ of water and mixing. Approximately $0.3 \mathrm{~kg}$ of water was bound in the starting biomass charge. The white liquor was used to deacetylate $3.3 \mathrm{~kg}$ of corn stover $(3.0 \mathrm{~kg}$ dry). After deacetylation, $23.7 \mathrm{~kg}$ of the weak black liquor was recovered and $5.4 \mathrm{~kg}$ of deacetylated corn stover at $\sim 50 \%$ solids was recovered. Therefore, in batch $2,6.3 \mathrm{~kg}$ of makeup water and $0.165 \mathrm{~kg}$ of makeup sodium hydroxide was added to the weak black liquor from batch 1 , because the $\mathrm{pH}$ was measured at 6.43 suggesting that all of the sodium hydroxide was neutralized by the acetic acid saponified during the deacetylation step. This deacetylation process was repeated 6 times in the current study and a total of $59.7 \mathrm{~kg}$ of water was used generating/regenerating the deacetylation white liquor.

In addition, wash water was used in a reverse counter-current direction to wash out the spent chemicals and dissolved organic substances starting with batch 6 , as shown in Figure 2 (also known as counter-current washing). The initial washing water added to batch 6 was $30 \mathrm{~kg}$ including water entrained in the biomass. The wash liquor was drained and further separated from biomass using a screw press to $\sim 50$ wt $\%$ solids. This method is widely used in the pulp and paper industry, known as dilution/extraction. The washing efficiency is highly dependent on pulp consistency after pressing. A makeup clean wash water

TABLE 1 | Water consumption in the recycle of weak black liquors.

\begin{tabular}{lcccccc}
\hline Number of recycles & $\mathbf{1}$ & $\mathbf{2}$ & $\mathbf{3}$ & $\mathbf{4}$ & $\mathbf{5}$ & $\mathbf{6}$ \\
\hline Biomass loaded $(\mathrm{kg})$ & 3.3 & 3.3 & 3.3 & 3.3 & 3.3 & 3.3 \\
Dry biomass $(\mathrm{kg})$ & 3 & 3 & 3 & 3 & 3 & 3 \\
$\mathrm{NaOH}(\mathrm{kg})$ & 0.165 & 0.165 & 0.165 & 0.165 & 0.165 & 0.165 \\
Initial water added $(\mathrm{kg})$ & 29.6 & - & - & - & - & - \\
Makeup water added in & - & 6.3 & 6 & 7.1 & 5.1 & 5.6 \\
black liquor $(\mathrm{kg})$ & & & & & & \\
Initial wash water $(\mathrm{kg})$ & - & - & - & - & - & 30 \\
Makeup wash water $(\mathrm{kg})$ & - & 7 & 7 & 7 & 7 & - \\
Final pH of weak black & 6.45 & 7.39 & 7.51 & 7.66 & 9.13 & 9.37 \\
liquor & & & & & &
\end{tabular}


was added to guarantee $30 \mathrm{~kg}$ of washing liquor in the next batch of washing. The washing was stopped at batch 1 because the washing liquor contained a soluble solids content of $2.3 \%$, which was equivalent to the soluble solids content in the weak black liquor produced from batch 1 . The total wash water added in all the batches was $58 \mathrm{~kg}$.

Therefore, the total water consumption in this study is $118 \mathrm{~kg}$ for $18 \mathrm{~kg}$ of dry biomass, resulting in a water-to-biomass ratio of $6.5: 1$ (wt/wt). This ratio is much lower compared to the conventional single-stage batch deacetylation method used in past publications, which is $\sim 20: 1$ (wt/wt). This recycling strategy can be optimized with displacement washing, with lower water usage and improved washing efficiency, or by employing an inclined, continuous screw counter-current deacetylation with improved washing strategies.

This recycling strategy is found arguably better than the high solids deacetylation steps carried out at 30\% total solids (Shekiro et al., 2016). In that study, using a 3:1 water-to-biomass ratio in the single-stage deacetylation step and a similar 3:1 ratio in the single-stage washing step, the total water-to-solid ratio is $6: 1$. However, the higher solids deacetylation scenario requires energy-intensive agitation, and difficult separations, and may not be practical in commercial-scale production.

\section{Effect of Recycling Black Liquor on Deacetylation Process}

Our goal for recycling of the deacetylation liquor is to increase the solids to $10-15 \%$ total solids to allow efficient evaporation and reduce energy consumption in the concentration of the black liquor. The weak black liquor from Kraft pulping contains $\sim 15 \%$ total solids-mainly lignin, degraded hemicelluloses (peeling reactions), and spent chemicals (sodium). The soluble solids of a typical weak black liquor from our deacetylation pretreatment is $\sim 2-3 \%$. Figure 3 shows the effect of black liquor recycling on total solids and soluble solids. Total solids contain soluble solids and insoluble biomass fines that are collected in the drain liquor and squeezate liquor from the screw press. The total solids increased from 3.5 to $10.3 \%$, while soluble solids increased from 2.4 to $8.9 \%$., Both total and soluble solids did not linearly increase with the increasing number of recycles. For the first three runs, the soluble solids increased by $\sim 2 \%$, while the solids increased by an average $0.8 \%$ for the last three runs. The decreased rate of accumulation of soluble solids shows the dissolution reaction of biomass is inhibited by the accumulated dissolved components. We hypothesize three things. First, deacetylation and certain delignification reactions are reversible reaction under alkaline conditions. The accumulation of the reaction products by recycling black liquor will eventually reach the equilibrium point, thus stopping the reactions. Second, sugar dissolution is controlled by the solubility, especially for the xylooligosaccharides. We postulate that during deacetylation, some xylan is solubilized as xylooligosaccharides (measured by HPLC for monomeric and total sugar assaysthe soluble sugars are primarily oligosaccharides) and eventually reaches the solubility limitations, thus reducing xylan losses in subsequent deacetylation batches. Third, the dissolved lignin

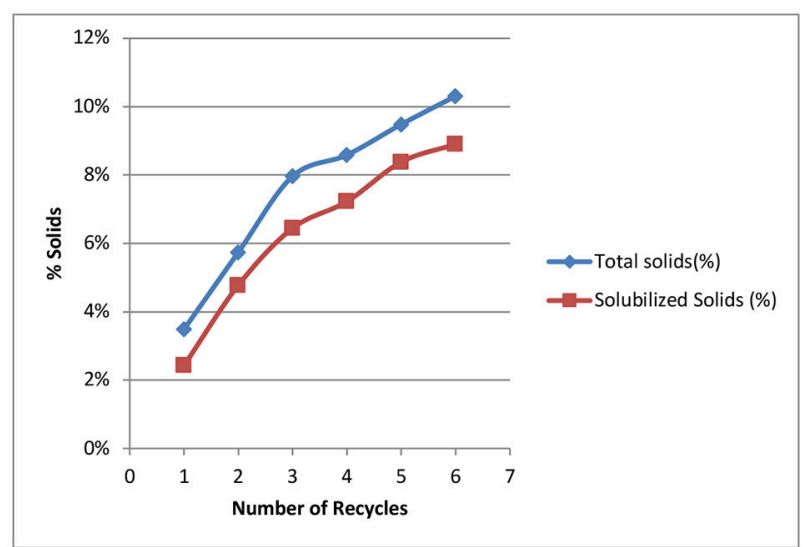

FIGURE 3 | Effect of number of recycling on total solids and soluble solids in the recycled black liquors.

and hemicellulose can be adsorbed by the biomass, thus affecting enzymatic hydrolysis. Due to electrostatic forces, the dissolved lignin-carbohydrate complexes compounds could precipitate on biomass surfaces, especially at the end of the deacetylation when the $\mathrm{pH}$ is reduced to near neutrality (Ban and van Heiningen, 2011). According to the Langmuir adsorption equation, the adsorption rate increases at a higher concentration of solids, resulting in lower soluble solids in the liquor phase.

Figure 4 shows the accumulation of solids in the wash liquor following batch-wise counter-current washing. Because the added wash water washes the deacetylated biomass in a counter-current direction, batch 6 wash liquor contains the lowest soluble solids. And the soluble solids increased until the washing liquor cycles to batch 4 followed by a slight decrease due to makeup washing water and lower solids content in deacetylated black liquor in batch 3 and 2. The highest solids in the washing liquors occurs around batch 4 . The washing is stopped at batch 1 where the soluble solids of the black liquor from batch 1 is only $2.4 \%$, equivalent to the soluble solids in the wash liquors out of batch 2 at $2.3 \%$.

Figure 5 shows the alkali and alkaline earth metal accumulations in the black liquors as a function of recycle. The sodium concentration increases from 3.17 to $12 \mathrm{~g} / \mathrm{L}$. As can be seen in Table 1, the first batch of deacetylation is conducted with $0.165 \mathrm{~kg}$ sodium hydroxide in $30 \mathrm{~kg}$ of water, resulting in $3.17 \mathrm{~g} / \mathrm{L}$ of sodium. Therefore, the analytical result from the inductively coupled plasma analysis for the first batch corresponded to the initial sodium concentration that had been loaded. The later recycle batches where limited amounts of makeup water were added due to absorption of water by the biomass decreased the amount of dilution of the sodium. Therefore, the sodium carried over from the last batch was diluted in the wash process, showing an incremental increase in the rate of sodium accumulation at $\sim 1.6 \mathrm{~g} / \mathrm{L} /$ recycle.

Potassium accumulation in the deacetylation weak black liquor is derived from extracting the soluble ash components of 
biomass. For every batch recycle, $\sim 0.36 \mathrm{~g} / \mathrm{L}$ of potassium was extracted. The total amount of potassium extracted is $\sim 3.6 \mathrm{~g} / \mathrm{kg}$ of corn stover. The dissolution rate of potassium is not affected by the number of recycles. Potassium is a possible valuable byproduct of the biorefinery, where it can be added back to the soil as an essential fertilizing agent to supplement the world's dwindling supplies of potassium. Calcium is another soluble ash component dissolved from biomass in the deacetylation step. In this study the dissolution and accumulation of calcium is low, with an average calcium accumulation of $0.06 \mathrm{~g} / \mathrm{L}$, because most of the calcium is tied up in the insoluble structural ash component in the corn stover feedstock.

Figure 6 shows the accumulation of sugars, lignin, and acetic acid in the black liquors with most of the soluble sugars in the oligomeric form. The dissolution and accumulation of glucan is the lowest among all the sugars solubilized, with the final glucan concentration of $0.9 \mathrm{~g} / \mathrm{L}$ achieved after recycling the weak black liquors six times. The accumulation of glucan is also linearly correlated with the number of batch recycles. Soluble xylan shows the highest sugar concentrations at $\sim 6 \mathrm{~g} / \mathrm{L}$ after the final recycle batch, while arabinan and galactan accumulate to 5 and $2 \mathrm{~g} / \mathrm{L}$, respectively. All three hemicellulose-derived oligomeric sugars

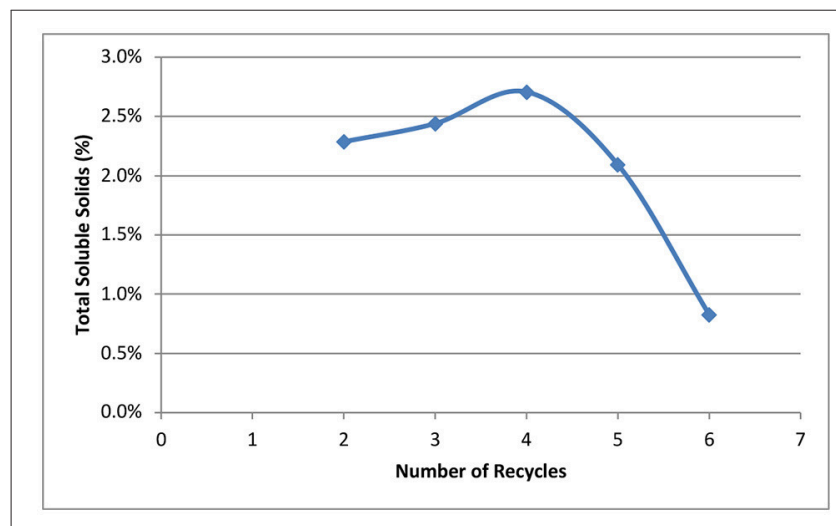

FIGURE 4 | Effect of number of recycling on soluble solids in the wash liquors.

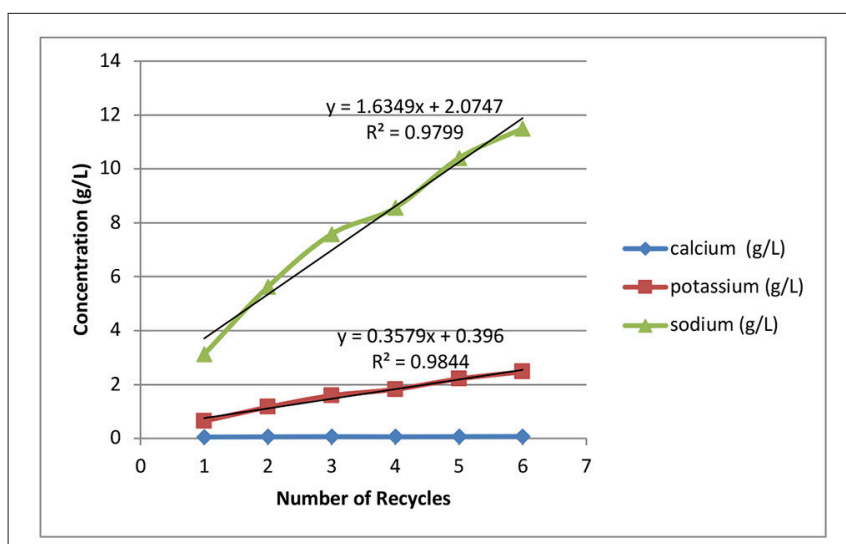

FIGURE 5 | Effects of weak black liquor recycling on the accumulation of sodium, potassium, and calcium in the recycle weak black liquors. are not linearly correlated to recycle batch number, especially when the last three recycles were performed. We hypothesize that xylan, arabinan, and galactan are all polysaccharides with limited solubility. The dissolution of soluble sugars slows down with an increased number of recycles. At a higher number of recycles, the adsorption of dissolved hemicellulose onto solid biomass starts to take effect with increasing hemicellulose concentrations in the solution. The reduced dissolution of hemicelluloses with each new batch at increased black liquor recycle batch number is beneficial in preserving biomass sugars for downstream sugar utilization.

The accumulation of lignin is also shown in Figure 6, displaying a linear correlation between lignin concentration and the number of recycles. The lignin concentration was found to be as high as $20 \mathrm{~g} / \mathrm{L}$ at the final batch, suggesting that lignin solubilization is not significantly affected by the number of recycles in our strategy. A similar linear trend is also found for acetate accumulation, resulting in $\sim 15 \mathrm{~g} / \mathrm{L}$ of acetic acid found in the black liquor from the final sixth recycle batch. The linear correlation between the number of recycles and the accumulation of lignin and acetate in the recycle black liquor shows that black liquor recycling has little impact on acetate and lignin removal under the current experiment conditions. By increasing the number of WBL recycles, the lignin and acetate can increase in concentrations without significantly affecting the removal of lignin and acetate.

Figure 7 shows the correlation between sodium and organic matter accumulation. Lignin and acetate accumulation is roughly linearly correlated with sodium accumulation, with correlation coefficients $\left(R^{2}\right)$ equal to 0.9938 and 0.9899 , respectively. For the dissolved sugars cases, the data indicate that sugar dissolution is more controlled by oligomer solubility than sodium concentration. It's also interesting to note that the acetic acid to sodium $(\mathrm{w} / \mathrm{w})$ ratio was found to be $1.22: 1$, suggesting a molar ratio of acetic acid to sodium of $\sim 1: 2$, indicating there

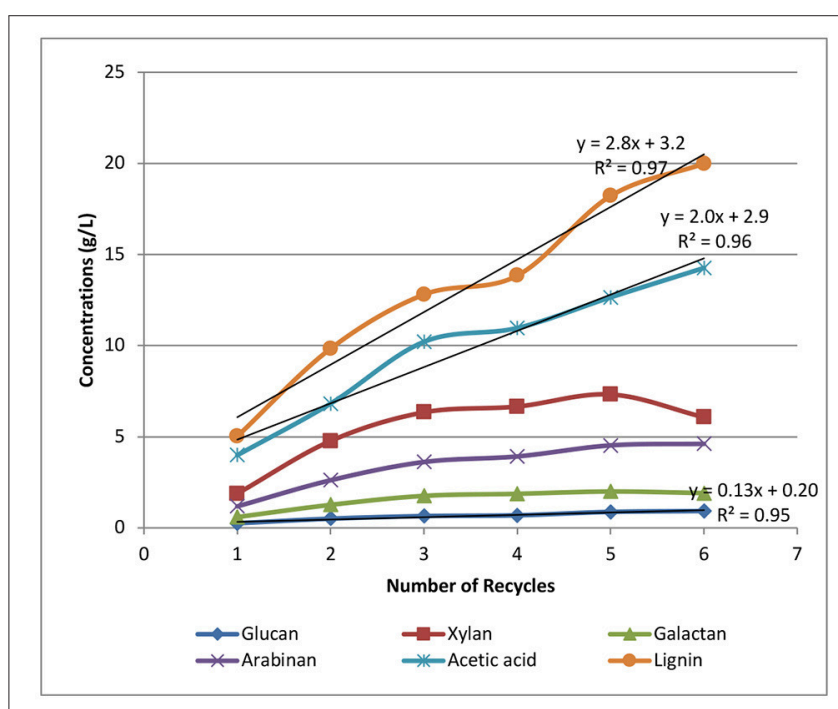

FIGURE 6 | Effects of weak black liquor recycling on the accumulation of sugars and acetic acid in the recycle liquors. 
were other sodium salts formed in addition to sodium acetate formed by saponification of the acetyl groups and by the neutralization by sodium hydroxide in the deacetylation black liquor.

Figure 8 shows the biomass component dissolution for every single stage of the deacetylation. The dissolution was calculated based on each component in the native biomass. The dissolution of glucan was $\sim 0.5-0.8 \%$ only for soluble glucose and sucrose and only the amorphous cellulose was dissolved during deacetylation. Xylan dissolution increased from 6 to $10 \%$ in the first two recycle batches and gradually decreased to $0.7 \%$ loss in the sixth batch. The dissolution of arabinan also displayed an initial increase from 35 to $49 \%$ in the first two batches followed by gradually decreasing from 44 to $27 \%$ in the next four batches. The increase of sugar dissolution from batch 1 to batch 2 was possibly due to the residual alkaline in the batch 1 , which increased the initial and final $\mathrm{pH}$ of batch 2 leading to a increased sugar dissolution. The decrease from recycle batch 3 to recycle batch 6 suggests the sugar dissolution was inhibited by solubility and potentially reabsorption of the xylan polysaccharides (Fengel and Wegener, 1984). Lignin dissolution averaged 35\% with a standard deviation of $\pm 5 \%$. The yields of acetic acid dissolution were all more than $120 \%$. This $>100 \%$ acetate removal shows a potentially underestimated acetyl group component from the analysis of the native biomass (Sluiter et al., 2008a). Alkaline conditions are more effective at saponifying and removing acetyl groups from biomass compared to acid hydrolysis of the ester functional groups. The scattered results of acetic acid were also caused by baseline interference raised by other co-eluted organic acids.

\section{Effects of Recycling Weak Black Liquor on Sugar Yields During Enzymatic Hydrolysis}

After deacetylation, corn stover was mechanically refined with two passes through a small Szego mill to optimize the enzymatic hydrolysis yields. In the past, we have obtained enzymatic hydrolysis yields close to $90 \%$. However, the deacetylated corn stover in the previous work was refined using a $36^{\prime \prime}$ pilot-scale disc refiner, or a combination of the disc refiner and Szego

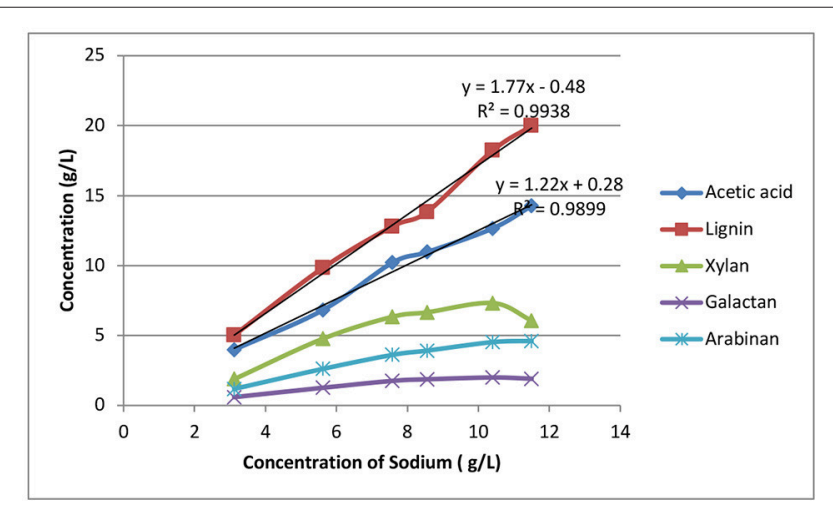

FIGURE 7 | The correlation between weak black liquor recycle and sodium and organic substances extracted from fresh biomass. mill (Chen et al., 2014). We found that a significant amount of unreacted hard kernels in the pretreated corn stover that were unable to be disintegrated using a double pass through the Szego mill. The enzymatic hydrolysis using the unbroken deacetylated hard kernels showed only $33 \%$ glucose and $31 \%$ xylose yields after 7 days (data not shown here). Therefore, the presence of the hard kernel reduces the overall yields of sugar in enzymatic hydrolysis experiments. The residual hard kernels after high solids enzymatic hydrolysis are shown in Figure 9, as it is apparent they were not touched by mechanical refining or enzymatic digestion.

The effects of recycling WBL from deacetylation on sugar yields are shown in Figure 10. The glucose and xylose yields in enzymatic hydrolysis were in the range of $68-78 \%$ and $64-$ $74 \%$, respectively. The sugar yields were all $10-15 \%$ lower than those previously reported for the multistage mechanical refining. As discussed above, the lower yields were mainly caused by the

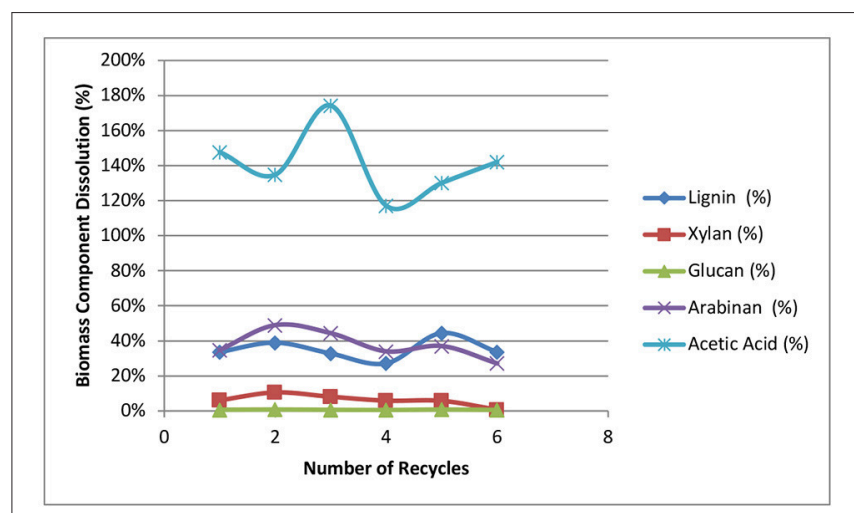

FIGURE 8 | The effects of recycling weak black liquors on biomass component dissolution.

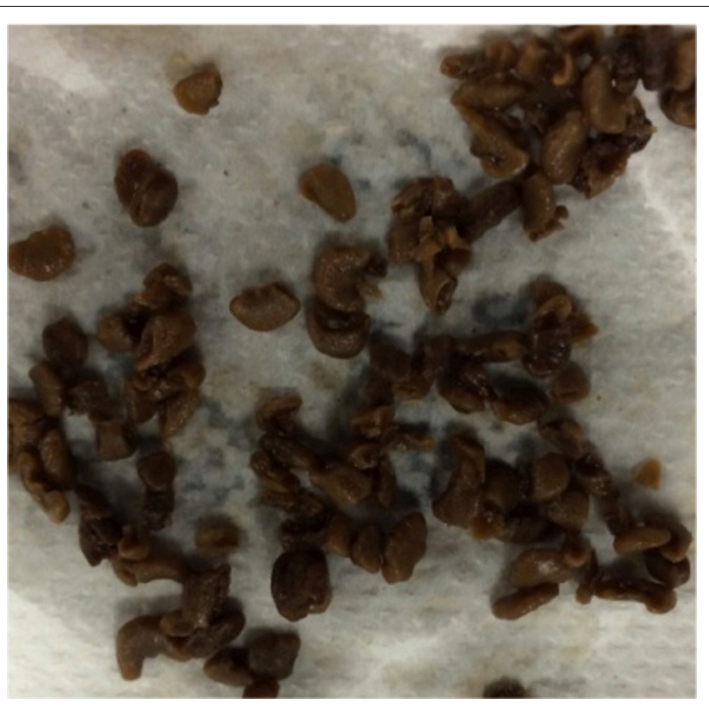

FIGURE 9 | The undigested hard kernels after enzymatic hydrolysis of DMR corn stover feedstock. 
undigested hard kernels that were not refined in the double pass through the Szego mill. Interestingly, these kernels were found to be highly digestible if they were first refined using a disc refiner, followed by refining in the Szego mill. We speculate that size reduction of all biomass anatomical fractions is needed to improve sugar yields.

Besides the lower yields caused by undigested corn kernels, recycling the weak black liquors did show some negative effects on sugar yields. The highest glucose yield occurred at batch 1 where clean white liquor was used and no washing was performed. The second highest glucose yield occurred at batch 6 where washing with clean water was performed. The lowest glucose yields occurred for batches 2, 3, 4, and 5, showing almost the same glucose yields across all batches with insufficient washing. The glucose and xylose yields for batches 2-6 followed a reversed trend of dissolved lignin in the surrounding liquor phase of the DMR corn stover slurry prior to enzymatic hydrolysis, showing the dissolved lignin after deacetylation will have a negative impact on sugar yields when it is carried over to the enzymatic hydrolysis stage. However, batch 1, where no washing is available, does not follow this hypothesis indicating the sugar yields are affected by other unknown reasons.

\section{Effects of Recycling Black Liquors on Ethanol Fermentations}

Sodium is one of the critical inhibitors for Zymomonas fermentation, as this microorganism has low tolerance to inorganic ions (Vriesekoop et al., 2002). The sodium from deacetylation will not be carried over to enzymatic hydrolysis and fermentation if one can use unlimited amounts of wash water to achieve very high washing efficiencies. However, it's not realistic in industrial applications due to the costs of both fresh water and wastewater treatment. A compromise is needed between washing efficiency and the amount of wash water used; the former directly affects the sodium content in biomass hydrolyzates. Figure 11 shows the metal ions in the biomass hydrolyzate prior to fermentation. Sodium content is around $1.8 \mathrm{~g} / \mathrm{L}$ in batch 1 hydrolyzate, which later reaches a maximum concentration in batch 3 at $\sim 1.9 \mathrm{~g} / \mathrm{L}$. The lowest sodium content is found in batch 6 at $\sim 1.4 \mathrm{~g} / \mathrm{L}$ because it is washed with fresh water. The amount of sodium in the biomass hydrolyzate liquors shows $\sim 20 \%$ sodium loss based on initial sodium loading due to low efficiency washing.

Potassium is the second largest inorganic ion in the hydrolyzate liquors and keeps almost constant concentration of $\sim 0.4 \mathrm{~g} / \mathrm{L}$. Calcium, magnesium, and iron are all in lower concentrations ranging from $\sim 0.1$ to $0.3 \mathrm{~g} / \mathrm{L}$.

The effect of WBL recycling on ethanol fermentations using rZymomonas is shown in Figure 12. Ethanol process yields were in the range between 85 and $92 \%$, showing the current sodium content has limited impact on ethanol yields. However, due to the relatively low sugar concentrations in the hydrolyzate liquors, the final ethanol titers were all around $60 \mathrm{~g} / \mathrm{L}$ (data not shown). It is not clear if this level of sodium will affect ethanol yield at higher sugar/ethanol concentrations. In addition, further investigation is needed for phenol-introduced inhibition, as it is reported that lignin-derived phenolic compounds are strong inhibitors to Acetone-Butanol-Ethanol (ABE) fermentation (Guan et al., 2018).

\section{WBL Thickening and Its Effect on Viscosity}

In the current NREL design case of hydrocarbon fuel production from biomass, the lignin content of the biomass is eventually combusted in a boiler to generate heat, power, and steam to supply the biorefinery process (Biddy and Jones, 2013). The lignin source from the DMR process came from two core unit operations: the deacetylation/dilute alkaline pretreatment and the solid liquid separation of enzymatic hydrolyzed biomass slurry. The deacetylation black liquor contains up to $30-40 \%$ of the original content of lignin in the biomass. Two strategies to increase lignin content in the WBL: Increasing the severity of alkaline pretreatment to release more lignin, increasing the lignin content in the black liquor could be much higher. Secondly, concentration of the solids in the WBL from the

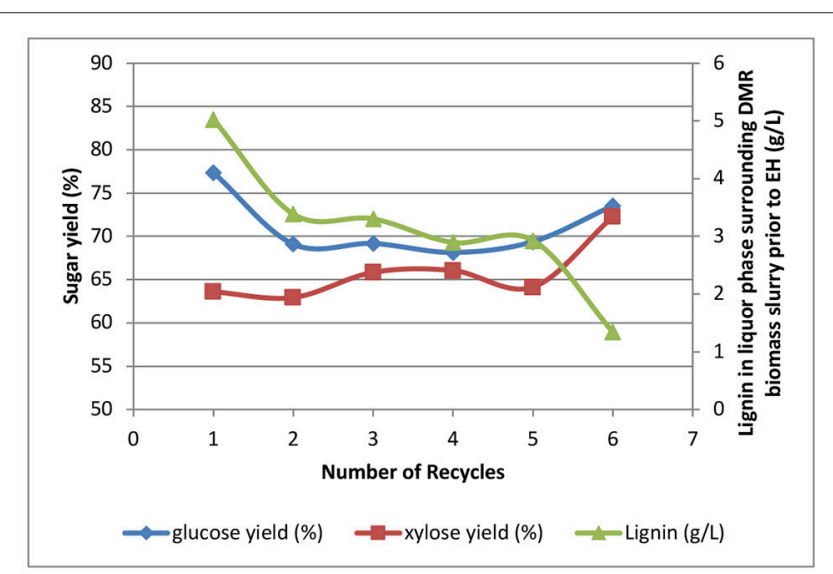

FIGURE 10 | Effects of recycling weak black liquors on enzymatic hydrolysis yields and lignin solubilization.

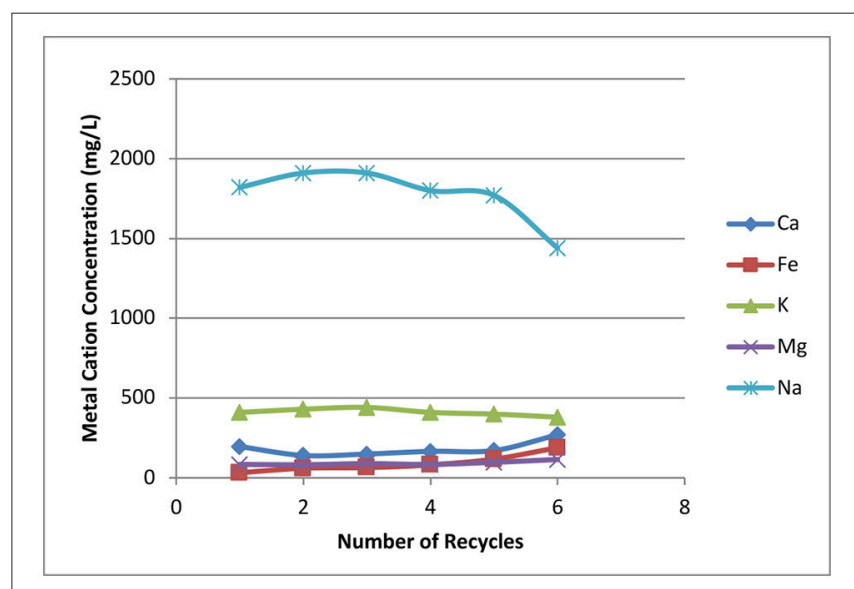

FIGURE 11 | Effects of recycling weak black liquor on inorganic ion concentrations in biomass hydrolyzate liquors prior to fermentation. 
deacetylation/alkaline pretreatment enabling the possibility of black liquor combustion or gasification.

There are two critical properties of the concentrated black liquor affecting the operation of the recovery boiler: (1) viscosity and (2) boiling point rise (BPR). In the Kraft process, the thick black liquor shows non-linear behavior with viscosity and BPR. If the WBL from the Kraft process is concentrated to $\sim 70 \%$ total solids, the viscosity of the TBL has been reported to be as high as 88 centipoise $(\mathrm{cP})$ even at $127^{\circ} \mathrm{C}$. The high viscosity of the concentrated black liquor requires liquor heat treatment to lower the liquor viscosity and ease the operation.

In a biorefinery process, the biggest challenge of using black liquor from the deacetylation/alkaline pretreatment step is the high content of hemicellulose sugars in herbaceous biomass, which may dissolve in high yields during dilute alkali pretreatment, and result in a high viscosity concentrated black liquor. However, these soluble sugars make the black liquor hard to flow at higher solids. In this research, we investigated the viscosity of concentrated WBL from the deacetylation and recycling process to understand its potential impact on black liquor utilization and combustion. The thin black liquor from batch 6 ( $\sim 10 \mathrm{wt} \%$ solids) is concentrated in a rotary evaporator to a final solids concentration of $\sim 65 \%$ total solids, which is required as the minimum solids content for combustion in a recovery boiler.

Figure 13 is a photograph of the visual observation of the concentrated black liquor ( $\sim 65 \%$ solids) at room temperature, indicating that the concentrated black liquor is flowable, but very viscous compared to water.

Figure 14 shows the effect of temperature on the viscosity of the concentrated black liquor from the sixth recycle experiment at $\sim 65 \%$ total solids. At room temperature, the black liquor has a viscosity of 2,000 cP, which decreases to $154.8 \mathrm{cP}$ at $100^{\circ} \mathrm{C}$. Higher temperature is also applied to TBL in an attempt to compare with the literature-reported viscosity of pulping black liquor at $127^{\circ} \mathrm{C}$. However, due to evaporation of the TBL using the atmospheric pressure cell, we were unable to accurately measure the viscosity of the TBL above $100^{\circ} \mathrm{C}$. Therefore, a pressurized cell will be used in the future.

\section{Effect of WBL Recycling on Minimum Ethanol Selling Price (MESP)}

Recycling of the dilute alkali deacetylation black liquor opens the door for efficient utilization of the waste lignin and acetate stream to produce value-added products. More importantly, recycling dilute alkali deacetylation black liquor reduces water and energy usage and thus reduces the production costs. Four potential scenarios were modeled in this report including: (1) deacetylation at $10 \%$ solids without washing and recycling; (2) deacetylation at $10 \%$ solids with washing and recycling; (3) deacetylation at $30 \%$ solids with washing but without recycling; and (4) deacetylation at 30\% solids without washing and recycling. Table 2 summarizes water and energy usage as well as final MESP of the four different scenarios calculated from the model.

Dilute alkali deacetylation at $10 \%$ solids has its pros and cons. The advantage of dilute alkali deacetylation under low solids conditions is that it requires much less mixing energy and is easier to be realized at commercial scale in a batch stirred tank reactor. On the other hand, the low solids process requires larger sizes of reactors, higher water usage, and higher steam usage. Deacetylation at $30 \%$ solids, however, is difficult to scale up to the industrial scale due to high requirements for mixing energy. In addition, deacetylation at 30\% solids without washing will not be able to separate the dissolved acetate and lignin from the slurry solids, leading to lower sugar and product yields. Therefore, recycling the dilute black liquor is more likely to be practically implemented at the commercial scale.

As shown in Table 2, deacetylation at 30\% solids with washing but without recycling has the highest water usage. At a 2,000-ton (dry) biomass/day plant, the water used in deacetylation stage is $\sim 750$ ton/h. If deacetylated at $10 \%$ solids without washing and

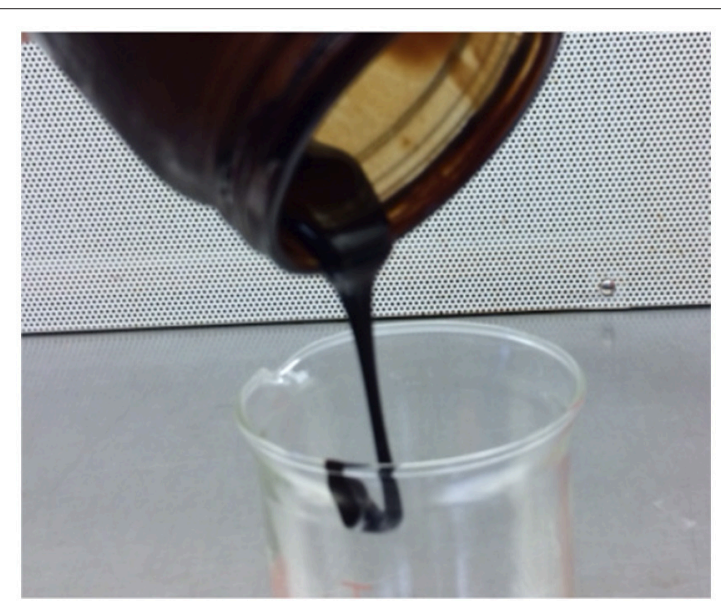

FIGURE 13 | Visual observation of thickened black liquor.

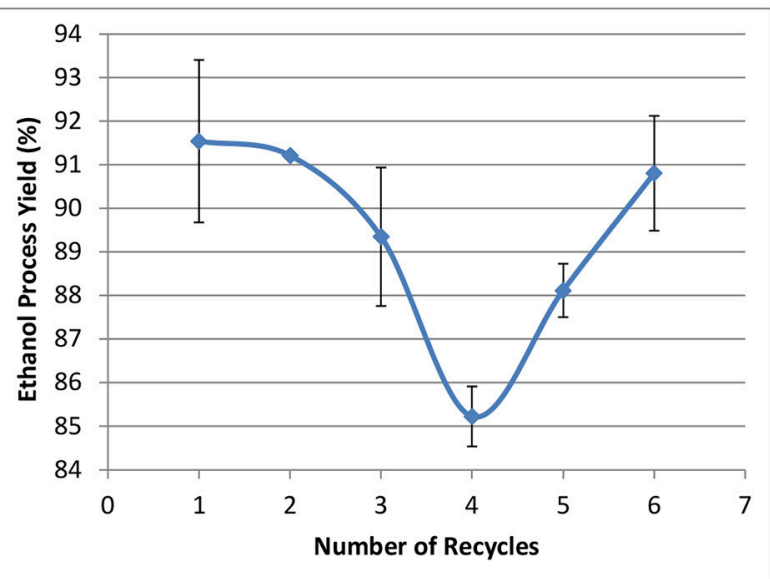

12 Effect of recycling weak black liquors on ethanol process yields. 


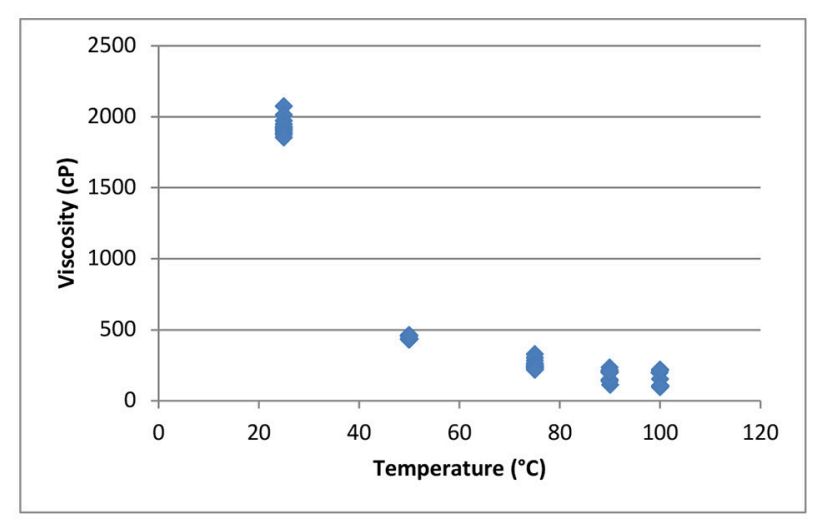

FIGURE 14 | Effect of temperature on the viscosity of concentrated recycled black liquor (65\% total solids).

TABLE 2 | Effect of recycling and washing on water and energy usage and MESP.

\begin{tabular}{|c|c|c|c|c|}
\hline \multirow[b]{2}{*}{ Deacetylation (total solids \%) } & \multicolumn{3}{|c|}{ Without recycle } & \multirow{2}{*}{$\begin{array}{c}\text { With recycle } \\
10\end{array}$} \\
\hline & 10 & 30 & 30 & \\
\hline Water for deacetylation (kg/h) & 666,667 & 166,667 & 166,667 & 166,667 \\
\hline $\begin{array}{l}\text { Wash water after } \\
\text { deacetylation (kg/h) }\end{array}$ & 0 & 563,117 & 0 & 67,620 \\
\hline Steam for A200 (kg/h) & 58,764 & 17,266 & 17,266 & 14,870 \\
\hline $\begin{array}{l}\text { Total water used for A200 } \\
(\mathrm{kg} / \mathrm{h})\end{array}$ & 728,107 & 748,949 & 358,054 & 404,178 \\
\hline MESP (\$/gal) & $\$ 2.32$ & $\$ 2.27$ & $\$ 2.21$ & $\$ 2.17$ \\
\hline
\end{tabular}

recycling, the water usage is similar to this amount. In another extreme case, when deacetylation occurs at $30 \%$ solids without washing, the water usage is less than half, showing 360 ton $/ \mathrm{h}$ usage. As discussed earlier, the no washing strategy will cause lower yields in enzymatic hydrolysis and fermentation due to the inhibition effects of acetate and lignin. However, if the dilute alkali deacetylation black liquor is recycled, the water usage for deacetylation at $10 \%$ solids with washing is only slightly higher than that of the $30 \%$ no washing case. The recycling saves as high as $45 \%$ of the water as compared to the no recycling process.

The recycling of dilute black liquor also significantly reduces the energy usage. As the black liquor recycles, the heat energy is conserved in the majority of the deacetylation liquor without loss or forced cooling. In non-recycling cases, the steam energy to heat up a large quantity of water from 25 to $80^{\circ} \mathrm{C}$ is mostly wasted during the washing step going to wastewater treatment. The energy saved by recycling the dilute alkali black liquor could be as high as $75 \%$.

To have a fair comparison for the effect of recycling on economics, the sugar and ethanol yields are fixed in the four cases described above. Thus, MESP is not affected by revenue but solely affected by the operational cost. As shown in Table 1, the highest
MESP is at $10 \%$ deacetylation with no washing and recycling, while the lowest MESP is at $10 \%$ deacetylation with washing and recycling. The cost savings calculated by the model range from 5 to 15 cents per gallon of ethanol. This result indicates that recycling of the dilute alkali black liquor could make the deacetylation process more economical.

\section{CONCLUSIONS}

In summary, the recycling of the WBL in the DMR process increases the concentrations of extracted components from corn stover biomass, making the black liquor from deacetylation a more valuable stream with upgradable lignin, acetate, and sugars. The increased sodium concentration in TBL also makes sense for sodium recovery through a causticization process similar to the Kraft process. In addition, the recycling strategy shows minimal impacts on downstream fermentation, indicating that the microorganisms used in current ethanol and proposed hydrocarbon production processes can tolerate the level of sodium and phenolic compounds in the recycled DMR hydrolyzate liquors where the sodium and lignin are carried over by incomplete washing during the recycling of the WBL. Moreover, the low viscosity of the concentrated black liquor shows that the recycled and evaporated deacetylation black liquor has similar rheological properties compared to pulping black liquor, thus could be pumped and processed at high solids concentrations. Finally, techno-economic analysis shows the recycling of weak black liquor could make the deacetylation process more economical.

\section{AUTHOR CONTRIBUTIONS}

$\mathrm{XC}$ designed and conducted the pretreatment experiment and drafted the manuscript. EK and NN help conduct the pretreatment and enzymatic hydrolysis experiment. RN conducted the fermentation. LT conducted TEA analysis. NC conducted the viscosity analysis. MT reviewed and revised the manuscript.

\section{ACKNOWLEDGMENTS}

This work was authored by Alliance for Sustainable Energy, LLC, the manager and operator of the National Renewable Energy Laboratory for the U.S. Department of Energy (DOE) under Contract No. DE-AC36-08GO28308. Funding provided by U.S. Department of Energy Office of Energy Efficiency and Renewable Energy Solar Energy Technologies Office. The views expressed in the article do not necessarily represent the views of the DOE or the U.S. Government. The U.S. Government retains and the publisher, by accepting the article for publication, acknowledges that the U.S. Government retains a nonexclusive, paid-up, irrevocable, worldwide license to publish or reproduce the published form of this work, or allow others to do so, for U.S. Government purposes. 


\section{REFERENCES}

Ban, W., and van Heiningen, A. R. P. (2011). Adsorption of hemicellulose extracts from hardwood onto cellulosic fibers I. Effects of adsorption and optimization factors. Cell. Chem. Technol. 45, 57-65.

Biddy, M., and Jones, S. (2013). Catalytic Upgrading of Sugars to Hydrocarbons Technology Pathway. Technical report: NREL/TP-5100-58055. Golden, CO: National Renewable Energy Laboratory.

Chen, X., Kuhn, E., Jennings, E. W., Nelson, R., Tao, L., Zhang, M., et al. (2016). DMR (deacetylation and mechanical refining) processing of corn stover achieves high monomeric sugar concentrations (230 g L-1) during enzymatic hydrolysis and high ethanol concentrations (>10\% v/v) during fermentation without hydrolysate purification or concentration. Energy Environ. Sci. 9, 1237-1245. doi: 10.1039/C5EE03718B

Chen, X., Shekiro, J., Franden, M., Wang, W., Zhang, M., Kuhn, E., et al. (2012). The impacts of deacetylation prior to dilute acid pretreatment on the bioethanol process. Biotechnol. Biofuels 5:8. doi: 10.1186/1754-6834-5-8

Chen, X., Shekiro, J., Pschorn, T., Sabourin, M., Tao, L., Elander, R., et al. (2014). A highly efficient dilute alkali deacetylation and mechanical (disc) refining process for the conversion of renewable biomass to lower cost sugars. Biotechnol. Biofuels 7:98. doi: 10.1186/1754-6834-7-98

Darmawan, A., Ajiwibowo, M. W., Yoshikawa, K., Aziz, M., and Tokimatsu, K. (2018). Energy-efficient recovery of black liquor through gasification and syngas chemical looping. Appl. Energy 219, 290-298. doi: 10.1016/j.apenergy.2018.03.033

Fengel, D., and Wegener, G. (1984). Wood - Chemistry, Ultrastructure, Reactions. New York, NY: W. de. Gruyter.

Guan, W., Xu, G., Duan, J., and Shi, S. (2018). Acetone-Butanol-Ethanol production from fermentation of hot-water-extracted hemicellulose hydrolysate of pulping woods. Industr. Engi. Chem. Res. 57, 775-783. doi: 10.1021 /acs.iecr.7b03953

Jeon, J.-W., Zhang, L., Lutkenhaus, J. L., Laskar, D. D., Lemmon, J. P., Choi, D., et al. (2015). Controlling porosity in lignin-derived nanoporous carbon for supercapacitor applications. ChemSusChem 8, 428-432. doi: $10.1002 /$ cssc. 201402621

Laskar, D. D., Tucker, M. P., Chen, X., Helms, G. L., and Yang, B. (2014). Noble-metal catalyzed hydrodeoxygenation of biomass-derived lignin to aromatic hydrocarbons. Green Chem. 16, 897-910. doi: 10.1039/c3gc4 $2041 \mathrm{~h}$

Mohagheghi, A., Dowe, N., Schell, D., Chou, Y., Eddy, C., and Zhang, M. (2004). Performance of a newly developed integrant of Zymomonas mobilis for ethanol production on corn stover hydrolysate. Biotechnol. Lett. 26, 321-325. doi: 10.1023/B:BILE.0000015451.96737.96
Naqvi, M., Yan, J., and Dahlquist, E. (2012). Energy conversion performance of black liquor gasification to hydrogen production using direct causticization with CO2 capture. Bioresour. Technol. 110, 637-644. doi: 10.1016/j.biortech.2012.01.070

Schell, D. J., Farmer, J., Newman, M., and McMillan, J. (2003). Dilute-sulfuric acid pretreatment of corn stover in pilot-scale reactor. Appl. Biochem. Biotechnol. 105, 69-85. doi: 10.1385/ABAB:105:1-3:69

Shekiro, J. III, Chen, X., Smith, H., and Tucker, M. (2016). Development and characterization of a high-solids deacetylation process. Sustain. Chem. Process. 4:6. doi: 10.1186/s40508-016-0049-6

Sluiter, A., Hames, B., Ruiz, R., Scarlata, C., Sluiter, J., and Templeton, D. (2008a). Determination of Sugars, Byproducts, and Degradation Products in Liquid Fraction Process Samples. National Renewable Energy Lab Report NREL/TP510-42623.

Sluiter, A., Hames, B., Ruiz, R., Scarlata, C., Sluiter, J., Templeton, D., et al. (2008b). Determination of Structural Carbohydrates and Lignin in Biomass. National Renewable Energy Laboratory Technical Report NREL/TP-510-42618.

Tran, H., and Vakkilainnen, E. K. (2008). The Kraft Chemical Recovery Process. Tappi. Available online at: http://www.tappi.org/content/events/ 08kros/manuscripts/1-1.pdf [Accessed].

Vriesekoop, F., Rasmusson, M., and Pamment, N. B. (2002). Respective effects of sodium and chloride ions on filament formation and growth and ethanol production in Zymomonas mobilis fermentations. Lett. Appl. Microbiol. 35 27-31. doi: 10.1046/j.1472-765X.2002.01137.x

Wang, H., Ruan, H., Feng, M., Qin, Y., Job, H., Luo, L., et al. (2017). Onepot process for hydrodeoxygenation of lignin to alkanes using ru-based bimetallic and bifunctional catalysts supported on zeolite, Y. ChemSusChem 10, 1846-1856. doi: 10.1002/cssc.201700160

Wang, H., Ruan, H., Pei, H., Wang, H., Chen, X., Tucker, M. P., et al. (2015). Biomass-derived lignin to jet fuel range hydrocarbons via aqueous phase hydrodeoxygenation. Green Chem. 17, 5131-5135. doi: 10.1039/C5GC01534K

Conflict of Interest Statement: The authors declare that the research was conducted in the absence of any commercial or financial relationships that could be construed as a potential conflict of interest.

Copyright (C) 2018 Chen, Kuhn, Nagle, Nelson, Tao, Crawford and Tucker. This is an open-access article distributed under the terms of the Creative Commons Attribution License (CC BY). The use, distribution or reproduction in other forums is permitted, provided the original author(s) and the copyright owner are credited and that the original publication in this journal is cited, in accordance with accepted academic practice. No use, distribution or reproduction is permitted which does not comply with these terms. 